\title{
Low colostrum yield in Jersey cattle and potential risk factors
}

\author{
K. Gavin, ${ }^{*}$ H. Neibergs, † A. Hoffman,‡ J. N. Kiser,† M. A. Cornmesser,† S. Amirpour Haredasht,§ \\ B. Martínez-López, $\$$ J. R. Wenz, ${ }^{*}$ and D. A. Moore*1 \\ *Department of Veterinary Clinical Sciences, and \\ †Department of Animal Sciences, Washington State University, Pullman 99164 \\ ¥Sunrise Veterinary Service, Dalhart, TX 79022 \\ $\S$ Center for Animal Disease Modeling and Surveillance (CADMS), Department of Medicine and Epidemiology, University of California, \\ Davis 95616
}

\begin{abstract}
Consumption of an adequate volume of high-quality colostrum is vital to a dairy calf's ability to survive and become a productive herd member. However, some dairy herds have reported a deficiency of colostrum production, which ranges from a low volume to no colostrum produced, by cows during fall and winter. Little information regarding this phenomenon exists. The purpose of this study was to characterize the syndrome and identify potential risk factors for low colostrum yield. A 2,500-cow Jersey dairy farm was enrolled in a prospective cohort study in May 2016, to evaluate possible effects of photoperiod, temperature, and cow factors on colostrum production. Dairy personnel were trained to collect, weigh, and evaluate colostrum quality. Information on parity, previous lactation length, previous 305-d mature-equivalent milk production, and dry period length were collected through the farm's dairy management software. Weather and photoperiod data were also collected. Over the year of enrollment, 2,988 eligible cows calved and had colostrum weights recorded and $38 \%$ were primiparous $(\mathrm{n}=1,143), 25 \%$ were in their second lactation $(\mathrm{n}=752)$, and $37 \%$ were in their third or greater lactation $(\mathrm{n}=1,093)$. The overall average colostrum yield was $6.6 \mathrm{~kg} / \mathrm{cow}$ in June 2016, $2.5 \mathrm{~kg} /$ cow in December 2016, and $4.8 \mathrm{~kg} /$ cow in May 2017. Multiparous cows had a larger decline in colostrum production between June and December (6.6 to $1.3 \mathrm{~kg} / \mathrm{cow}$ ) compared with primiparous animals (6.5 to $4.2 \mathrm{~kg} / \mathrm{cow}$ ). Overall, average colostrum production decreased by $0.17 \mathrm{~kg} / \mathrm{cow}$ per week during this time, $0.22 \mathrm{~kg}$ for multiparous cows and $0.08 \mathrm{~kg}$ for primiparous cows. A logistic regression model was constructed for all cows to evaluate effects of cow factors on low colostrum production ( $<2.7 \mathrm{~kg}$ at first milking).
\end{abstract}

Received December 18, 2017.

Accepted February 24, 2018.

${ }^{1}$ Corresponding author: damoore@vetmed.wsu.edu
Dry period length, calf sex, singleton or twin, age at freshening, month of calving and previous lactation length were significantly associated with the probability of low colostrum yield ( $<2.7 \mathrm{~kg}$ at first milking). A cross-correlation function analysis between the time series for colostrum yield and photoperiod revealed a high correlation at the time of calving and 1 mo prior, particularly for multiparous cows. A pedigree analysis showed that extreme colostrum yield (low vs. high) followed some sire lines. Low colostrum production in this herd could have an economic effect on the dairy and calf health and appears to have a strong seasonal and, potentially, a genetic component.

Key words: colostrum production, dairy cattle, photoperiod, pedigree analysis

\section{INTRODUCTION}

Colostrum feeding is a critical part of raising healthy calves, and to provide this cows must produce adequate amounts of colostrum with high concentrations of immunoglobulins, cytokines, nutritional elements, and growth factors (McGuirk and Collins, 2004). Calves not receiving sufficient $\mathrm{IgG}$, and therefore suffering from failure of passive transfer of immunity, can have morbidity and mortality risks up to 5 and 6 times higher than that of herd-mates experiencing successful passive transfer of immunity (Donovan et al., 1998). Additionally, successful transfer of passive immunity through the colostrum has been associated with improved ADG in heifers and increased milk production in cows (Faber et al., 2005).

Many factors are implicated in the production of high-quality colostrum, including dry period nutrition, dry period length, parity, season, and previous 305-d milk production. A recent study showed that cows fed balanced diets during the dry period produced colostrum with significantly greater IgG concentrations (96.1 vs. $72.4 \mathrm{mg} / \mathrm{dL}$ ) compared with cows fed at $150 \%$ of the required dietary energy level (Mann et 
al., 2016). Dry period length, milk production history, and parity have also been shown to affect colostrum immunoglobulin level. Cows with an 8- to 12-wk dry period were found to produce greater IgG concentration in their colostrum than cows with dry periods less than 8 wk in length, and cows with the highest previous 305-d milk yield also had the greatest colostrum IgG concentration (Dunn et al., 2017). In another study, cows in their fifth or greater lactation produced greater $\operatorname{IgG}$ concentration colostrum than lower-parity cows (Dunn et al., 2017). Season of calving has also been implicated as a factor involved in colostrum production. A study in Ireland found that cows calving in the winter produced colostrum with higher IgG levels than cows calving during the spring and fall months (Dunn et al., 2017). Although several factors that may influence the IgG content of colostrum have been studied, little information has been published on the potential risk factors for low colostrum volume in dairy cows.

Factors that may influence colostrum volume production include nutrition, dam health, and environmental conditions such as photoperiod. An ovine study by Swanson et al. (2008) found that ewes fed $100 \%$ of the NRC (2007) requirements from d 50 of gestation to parturition produced greater volumes of colostrum than ewes fed 60 or $140 \%$ of NRC requirements. A similar study with dairy cows evaluated the effect of dry period dietary energy level on colostrum production with inconclusive results. Cows fed control diets produced numerically less but not significantly different amounts of colostrum compared with cows fed at 125 or $150 \%$ of the required dietary energy level (Mann et al., 2016). Cow health is another factor implicated in colostrum production, as Maunsell et al. (1998) found, as cows with 2 or more mastitis events in late gestation experienced significantly reduced colostrum production at the next calving (1,313 vs. 2,647 mL).

In addition to cow nutrition and health, environmental conditions such as heat stress have been evaluated for effects on colostrum production. A study by Karimi et al. (2015) found no difference in colostrum volume from cows cooled by misters and fans during the dry period compared with those without cooling (Karimi et al., 2015). Unlike the previously mentioned factors, the effect of photoperiod on colostrum production has not been studied, although it does have a known role in milk production. Dry cows exposed to a short day photoperiod were observed to produce approximately $3.1 \mathrm{~kg} / \mathrm{d}$ more milk during the next lactation than cows exposed to a long day photoperiod (Dahl and Petitclerc, 2003). Manipulated photoperiod during the dry period did not affect colostral $\mathrm{IgG}$ concentrations in Holstein cows (Morin et al., 2010).
The genetics of an animal might also play a role in colostrum production. An ovine study by Pattinson and Thomas (2004) found that sire breed had an effect on colostrum yield in crossbred ewes; to our knowledge, this has not been evaluated in dairy cattle. Because dairy cattle have long been selected for milk production and not necessarily selected for colostrum production, there could be a genetic component to colostrum production that has gone undetected.

Although anecdotal reports from veterinarians, nutritionists, and dairy producers have indicated a periodic depression in colostrum production during fall months in North America (Litherland, 2009), little information is available in the literature about this condition. The objective of our prospective cohort study was to characterize seasonal low colostrum yield as observed on 1 large dairy and identify potential risk factors for this phenomenon.

\section{MATERIALS AND METHODS}

\section{Animals, Facilities, and Housing}

A Jersey dairy herd in Texas (about 2,500 lactating cows) was enrolled in a prospective cohort study in May 2016 due to its multiyear history of periodic low colostrum yield. Cows were loosely housed in naturally ventilated compost-bedded pack barns oriented in an east-west direction with weather curtains on the north sides. Pens inside the barns were $12 \mathrm{~m}$ wide and 46 to $183 \mathrm{~m}$ long with a $3.5-\mathrm{m}$ alley. Cows had free access to an outside paddock that was $24 \mathrm{~m}$ wide and the same length as the pen. Milking cow pens were harrowed and lime was applied twice daily, whereas dry cow and close-up calving cow pens were harrowed and limed once per day. During hot months, cows were cooled with a combination of soakers and fans in the holding pen and milking parlor. Cows were dried off weekly at approximately $60 \mathrm{~d}$ before their expected calving dates and moved to a far-off dry cow pen. Dry cows were moved into a close-up calving cow pen approximately 21 $\mathrm{d}$ before calving and pregnant heifers were moved into a separate close-up calving cow pen approximately $50 \mathrm{~d}$ before calving. The far-off dry cow pen was a naturally ventilated compost-bedded pack barn, with a 24 by 183 $\mathrm{m}$ outside pen and 300 headlocks. The primiparous and multiparous close-up calving cow pens were $12 \mathrm{~m}$ wide and 46 and $82 \mathrm{~m}$ long, respectively, with no outside access. The primiparous pen had 75 lockups, and the multiparous pen had 135 lockups. Shade from the barns was the method of cooling provided.

Cows were fed a TMR, balanced by a ruminant nutritionist, which mostly consisted of locally grown feeds. 
Table 1. Target ${ }^{1}$ nutrient specifications for rations fed to dry and close-up animals on 1 Jersey dairy farm across the study period from May 2016 to June 2017

\begin{tabular}{lccc}
\hline & \multicolumn{3}{c}{ Diet } \\
\cline { 2 - 4 } Component & Far-off cows & Close-up cows & Close-up heifers \\
\hline DMI (kg/cow per day) & 15.7 & 12.3 & 9.0 \\
CP (\% of DM) & 14.0 & 15.5 & 16.4 \\
ADF (\% of DM) & 27.6 & 22.3 & 24.1 \\
NDF (\% of DM) & 44.5 & 33.7 & 34.4 \\
NE $($ Mcal/kg DM) & 126.0 & 158.0 & 162.4 \\
Starch (\% of DM) & 11.5 & 16.7 & 4.2 \\
Fat (\% of DM) & 3.4 & -12.6 & 41.6 \\
DCAD (mEq/kg of DM) & 376.5 & & 41.48 \\
\hline
\end{tabular}

${ }^{1}$ Ration components might have changed over time, but the nutrient specifications listed did not vary significantly across the year.

The target nutrient specifications for dry and close-up calving cows (Table 1) did not vary significantly across time, although ingredients may have changed depending on feed availability. Lactating cows were restrained in headlocks for less than $1 \mathrm{~h} / \mathrm{d}$ for AI, vaccination, and cow movement purposes.

\section{Colostrum Harvesting Process}

The farm's 2 primary calving technicians were trained by research staff and the farm veterinarian on colostrum sampling technique, method of weighing colostrum using a hanging scale, and methods for recording this information on the calving sheets. The 2 primary calving technicians then trained auxiliary calving technicians to follow the same protocol detailed below. Adherence to protocols was monitored by the dairy manager and the herd veterinarian to minimize protocol drift.

Immediately after calving, cows were moved to a small $(2.5 \times 4.5 \mathrm{~m})$ pen and restrained with a stanchion. A 3 -mL (60 IU) i.m. dose of oxytocin was administered, a red leg band was attached to a hind leg, and the calving date was written with a paint stick on the cow's flank. Oxytocin was an existing farm protocol due to historical incidence of low to no colostrum production postcalving to rule out milk let-down as an issue. A gloved calving technician predipped the teats with a dodecylbenzene sulfonic acid product (Wash and Prep RTU, Ecolab Inc., St. Paul, MN), then the teats were stripped 5 to 6 times, dried with paper towels, and wiped with alcohol swabs. A portable milking unit was then used to milk the cow into a stainless-steel bucket. After milking, the cow's teats were dipped with a heptanoic acid product (Cynergy Pre-Post, Ecolab Inc.) and the cow was taken to a pen for newly calved cows, where she stayed for 2 to $3 \mathrm{~d}$. A 3- to 5 -mL sample of colostrum was collected for Brix refractometry analysis and the bucket and colostrum were weighed using a WeiHeng 50-kg Mini Digital Hanging Scale (WeiHeng
Digital Co. Ltd., Shenzhen, China). The colostrum was aliquoted into 3 L coloQUICK (Golden Calf Company LLC, Bloomer, WI) bags using a coloQUICK funnel. Bags were labeled with the date and Brix reading and pasteurized in the coloQUICK pasteurizer. The colostrum was then cooled in a mixture of ice and water and stored in a freezer. The cow's identification (ID) number, calving date, Brix reading, combined colostrum and bucket weight, calf sex and singleton or twin, calf ID number (if female), and calving technician were recorded on the calving sheets in the maternity area.

\section{Data Collection}

A custom report was created in the herd management software program (DHI Plus, DHI-Provo, Provo, UT) that included cow ID number, calving date, calving month, calving week, lactation number, lactation group, age at calving, dry period length, previous lactation 305-d mature-equivalent milk yield (305ME), previous lactation length, and previous calving date for all cows that calved during the previous 2 wk. This report was generated and exported to Microsoft Excel (Microsoft Corp., Redmond, WA) each week and then the previous gestation length was calculated. Calving sheets from the maternity pen were collected each week and the calf sex, singleton or twin, calving technician, Brix refractometer reading, and weight of the colostrum and the bucket were recorded into an Excel spreadsheet. The DHIA and calving sheet data sets were merged in the spreadsheet using cow ID number.

Environmental data came from 2 sources. Daily weather data (temperature and humidity) were obtained from Weather Underground (http://www .weatherunderground.com) and daily photoperiod data came from the United States Naval Observatory (http://www.usno.navy.mil/USNO) for the time periods under study. Temperature-humidity index (THI) was calculated using the formula 
$\mathrm{THI}=\mathrm{T}-\{0.55 \times[0.55 \times(\mathrm{RH} / 100)]\} \times(\mathrm{T}-58)$,

where $\mathrm{T}$ is the ambient temperature in degrees Fahrenheit and RH is relative humidity (Collier et al., 2012).

\section{Pedigree Data and Analysis}

An official American Jersey Cattle Association performance pedigree was obtained for each cow enrolled in the study. These pedigrees provided information on each cow's sire and dam as well as paternal and maternal grandsires and granddams (if available). A subset of cows $(\mathrm{n}=837)$ that calved between October 23, 2016, through January 21, 2017 (the lowest colostrum producing time period), was selected to investigate cattle relatedness. Because this time period was when a large proportion of cows experienced low yield, this subset was chosen to exclude potential effects of season. These 837 cows were further partitioned based on extreme colostrum weights, low colostrum $(<0.45 \mathrm{~kg} ; \mathrm{n}=102)$ and high colostrum $(>5.44 \mathrm{~kg} ; \mathrm{n}=112)$ yield, to better delineate differences in pedigrees. These 2 groups were then investigated to obtain pedigree data for 8 generations. This pedigree information was entered into Pedigree Explorer V6.0 (Wild Systems, Carlingford, Australia). Using Pedigree Explorer, the cows were investigated to determine if colostrum production was segregating by sire lines and, thus, if evidence of a genetic component to colostrum production could be determined. Sires that fathered 3 or more cows were included in a single-factor ANOVA with a significance threshold of $P<0.05$ to determine if colostrum weight segregated by sire line.

\section{Data Analysis}

Data were managed in Excel and Tableau (Tableau Software Inc., Seattle, WA) spreadsheets. Descriptive statistics were generated in the spreadsheet and univariate, bivariate, and multivariate analyses done using a statistical software program (SAS v. 6.1, SAS Institute Inc., Cary, NC). Continuous variables were evaluated for normality. Those that were not normally distributed were categorized based on their distribution. The relationship between Brix percentage and colostrum yield at first milking, controlling for some cow factors, was evaluated using the PROC GLM procedure. Days in lactation, parity, calf sex and singleton or twin, and calving month were included in the model and 1-way interactions were evaluated. Model selection was done with a forward stepwise selection process with assessment of the Akaike information criteria (AIC), with a choice of model with the smallest AIC value. Colostrum yield $(\mathrm{kg})$ for cows in parity $>1$ was dichotomized on the biological value of $2.7 \mathrm{~kg}$ of colostrum (of average quality) needed to feed a Jersey calf for potentially adequate transfer of passive immunity. Only cows were evaluated to examine potential effects of previous lactation factors on the probability of low colostrum production. A logistic regression analysis was done using the PROC LOGISTIC procedure. The variables chosen, based on previous studies of colostrum quality and yield, were added to the model and included calving age, calf sex and singleton or twin, calving month, previous days in lactation, previous days in the dry period, previous total milk production, and previous 305ME. Significance level of variables in the model were set at 0.05 . The AIC and $-2 \log$-likelihood values were evaluated for model fit, and the model with the smallest values was selected.

A cross-correlation function analysis was used to assess the relationship between the independent variables of photoperiod and THI at different monthly lags and the dependent variable of average weekly colostrum yield over the time series from June 1, 2016, to May 31, 2017. Cross-correlation function analysis is a standard method of estimating the degree to which 2 times series are correlated (Kendall and Ord, 1990). Specifically, the cross-correlation function (Box and Jenkins, 1976) was used to help evaluate which of the outputs (i.e., average of lactation 1 colostrum yield and average of lactation $>1$ colostrum yield) had the strongest linear relationship with the inputs (i.e., average of photoperiod hour and average of the maximum THI) using the methods described by Haredasht et al. (2013). The cross-correlation function is a representation of the linear correlation between an assumed input variable and the output at different lags (0 to $12 \mathrm{mo}$ ) plotted against this lag. The cross-correlation function analysis was performed using the Captain toolbox in Matlab (Taylor et al., 2007).

\section{RESULTS}

\section{Cows and Colostrum Quality}

From June 1, 2016, through May 31, 2017, a total of 3,070 cows calved. Eighty-two cows were removed from the study because they did not have colostrum weights recorded $(\mathrm{n}=75)$ or had incomplete information, such as lactation number $(\mathrm{n}=1)$, age at calving $(\mathrm{n}=1)$, and previous lactation records $(\mathrm{n}=5)$. Thirty-eight percent of the remaining 2,988 cows were primiparous $(\mathrm{n}=1,143), 25 \%$ were in their second lactation $(\mathrm{n}=$ 752 ), and $37 \%$ were in their third lactation or greater ( $\mathrm{n}=1,093)$. Technician was recorded for 2,793 of the calves' births. The 2 primary technicians were respon- 
sible for $82 \%$ of colostrum harvest from cows and a third technician was responsible for about $10 \%$. The 2 primary technicians missed collecting colostrum or calf data for 1.1 and $1.4 \%$ of the cows for which they were responsible, respectively, and the third technician did not miss collecting data from any of the cows for which he was responsible.

Of all the cows with mammary secretions at the first milking and a Brix evaluation done as a surrogate for colostrum quality $(\mathrm{n}=2781)$, the data for their Brix values were normally distributed with a mean of $25.9 \%(95 \%$ CI $=25.8,26.1)$, mode of $25.6 \%$, median of $25.9 \%$, and ranged from 9.5 to $38.6 \%$. The average Brix values was highest, on average, in first-lactation animals (Table 2). We found a statistically significant linear relationship between colostrum $(\mathrm{kg})$ and Brix percentage $(P<0.001)$, but colostrum yield explained only about $6 \%$ of the variation in Brix percentage. A generalized linear model for the outcome of Brix percentage included colostrum yield $(\mathrm{kg})$, calf sex and twinning, lactation group, and month of calving (Table 3 ). Although the effect of colostrum yield on Brix percentage was significant, the effect estimate was small. Calf and calving month had greater influences on Brix percentage.

\section{Colostrum Yield}

Average colostrum yield was $4.26 \mathrm{~kg}$ (range $=0$ to 26.5) and we noted a wide range of colostrum weights on a weekly basis (Figure 1). Overall, average colostrum yield was $6.6 \mathrm{~kg} / \mathrm{cow}$ in June, 2016, $2.5 \mathrm{~kg} / \mathrm{cow}$ in
December, 2016, and $4.8 \mathrm{~kg} / \mathrm{cow}$ in May, 2017 (Figure $1)$. On average, primiparous cows produced more colostrum than multiparous cows (Table $2 ; P<0.01$ ). Six percent of all multiparous cows produced no colostrum (no mammary secretions at first milking), whereas only $0.3 \%$ of primiparous cows produced no colostrum $(P<0.001)$. Multiparous cows had a larger decline in average weekly colostrum production between June and December of 2016 (6.6 to $1.3 \mathrm{~kg} / \mathrm{cow}$ ) compared with primiparous cows (6.5 to $4.2 \mathrm{~kg} /$ cow; Figure 2). Average colostrum production decreased by $0.17 \mathrm{~kg} /$ cow each week, $0.22 \mathrm{~kg}$ for multiparous cows and 0.08 $\mathrm{kg}$ for primiparous cows. More than $35 \%$ of cows with $>1$ lactation produced no colostrum (no mammary secretions at the first milking) in the month of December, compared with about $1 \%$ of first-lactation cows $(P<$ 0.001; Figure 3).

\section{Cow Factors Associated with Low Colostrum Yield}

Colostrum yield from cows with $>1$ lactation was categorized into 2 levels, $<2.7$ and $\geq 2.7 \mathrm{~kg}$, which is the amount needed (with average quality) to feed a newborn Jersey calf for potentially successful passive transfer of immunity. A logistic regression model for influence of cow factors on the probability of low colostrum production $(<2.7 \mathrm{~kg})$ was built in a forward, stepwise process. Variables used in the model were calving age, calf (male, female, or twins), dry period length (days), previous lactation $305 \mathrm{ME}(\mathrm{kg})$, previous lactation length (days), and calving month (days). In the analysis, none of the 1-way interactions were significant. Dry

Table 2. Descriptive statistics for 2,988 Jersey cows enrolled in a study to describe colostrum production over time, June 2016 through May 2017

\begin{tabular}{lcccc}
\hline Variable & Lactation & Mean & SD & Range \\
\hline Age at calving (mo) & 1 & 20.44 & 1.51 & $16-30$ \\
& 2 & 33.48 & 2.76 & $30-51$ \\
Dry period length (d) & $3+$ & 57.31 & 14.38 & $41-134$ \\
& 2 & 65.01 & 10.92 & $15-123$ \\
Previous 305ME ${ }^{1}(\mathrm{~kg})$ & $3+$ & 67.38 & 23.03 & $0-657$ \\
& 2 & 10,486 & 1,334 & $5,805-14,397$ \\
Previous lactation milk yield (kg) & $3+$ & 10,410 & 1,461 & $5,389-15,440$ \\
Previous lactation length (d) & 2 & 8,100 & 2,070 & $3,692-21,822$ \\
& $3+$ & 9,837 & 2,130 & $4,400-23,151$ \\
Gestation length (d) & 2 & 318.9 & 63.66 & $220-755$ \\
& $3+$ & 320.0 & 59.76 & $225-790$ \\
Average colostrum Brix reading ${ }^{2}(\%)$ & 2 & 283.1 & 5.03 & $259-307$ \\
& $3+$ & 283.0 & 5.87 & $223-306$ \\
Average colostrum weight (kg) & 1 & 26.6 & 3.68 & $12.7-38.5$ \\
& 2 & 25.0 & 3.61 & $13.1-37.4$ \\
& 1 & 25.8 & 4.78 & $9.5-38.6$ \\
& 2 & 4.92 & 2.66 & $0-17.53$ \\
& $3+$ & 4.09 & 3.23 & $0-24.15$ \\
& & 3.67 & 3.56 & $0-26.55$ \\
\hline
\end{tabular}

${ }^{1}$ Previous 305-d mature equivalent milk yield.

${ }^{2}$ Does not include cows that produced no colostrum. 


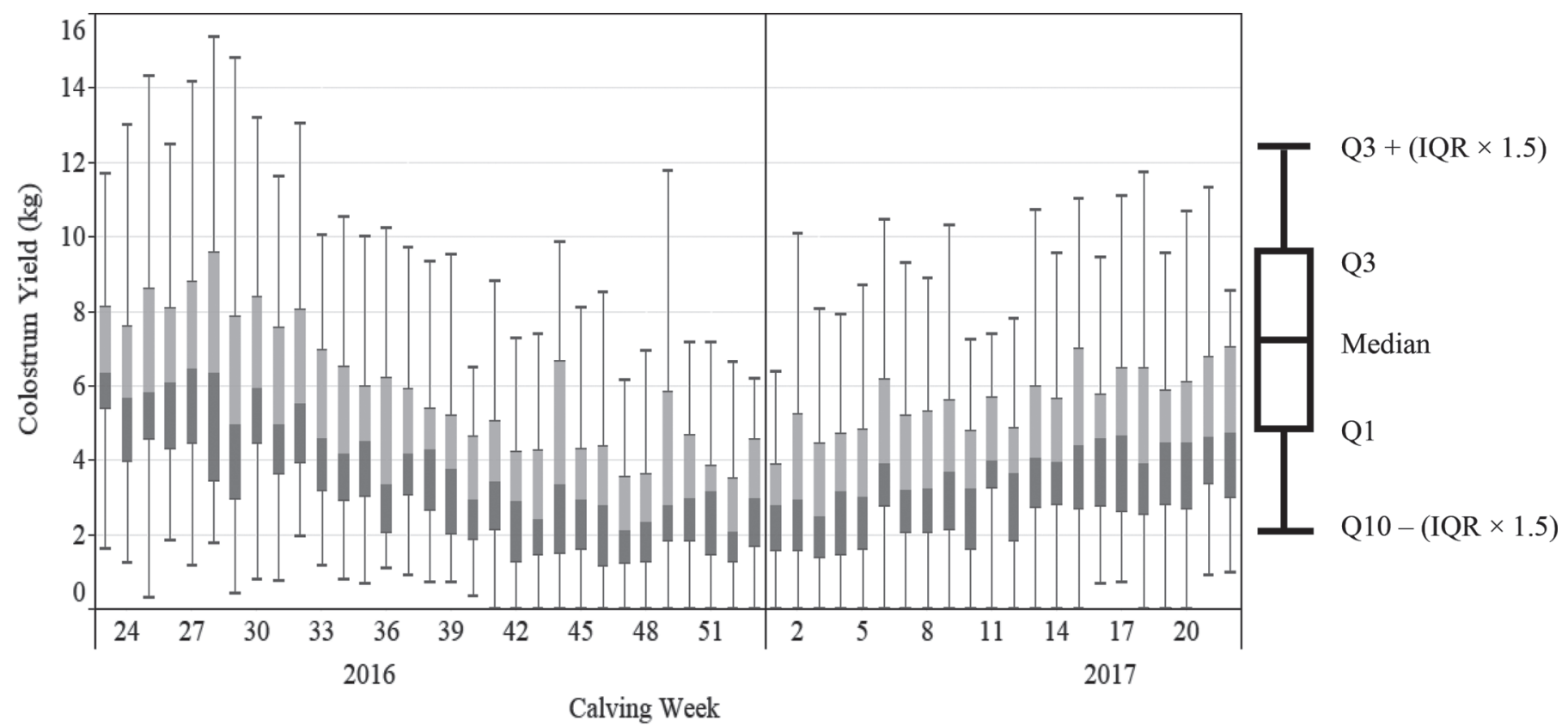

Figure 1. Box and whiskers plots of weekly average colostrum yield (kg) from 2,988 Jersey cows calving between June 2016 and May 2017. $\mathrm{Q}=$ quartile; $\mathrm{IQR}=$ interquartile range.

period length, calf type (female, male or twins), age at calving, calving month, and previous lactation length were associated with the probability of colostrum yield $<2.7 \mathrm{~kg}$ (Table 4). Compared with the youngest ages at calving, older cows had 1.38 to 2.27 times greater odds of colostrum yield $<2.7 \mathrm{~kg}$ (Table 4 ), controlling for other factors, including calving month. Compared with cows with twins, cows with female singletons had a slightly greater risk for low colostrum production. Month of calving had the greatest influence on the odds of low colostrum production in these cows. Although a longer dry period length and previous days in lacta-

Table 3. Results of multivariate linear regression analysis examining the association of Brix percentage in colostrum and colostrum yield, controlling for some cow factors

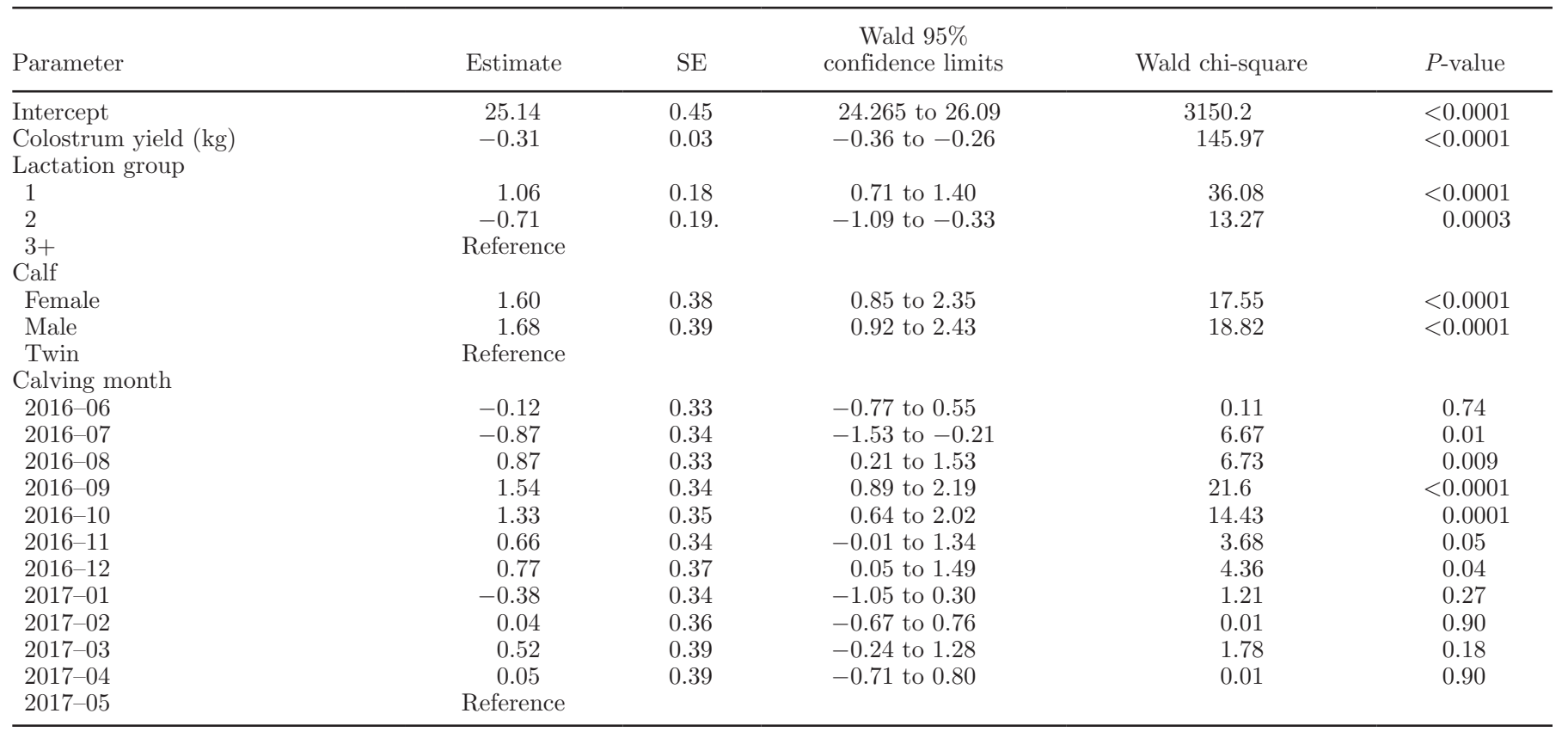




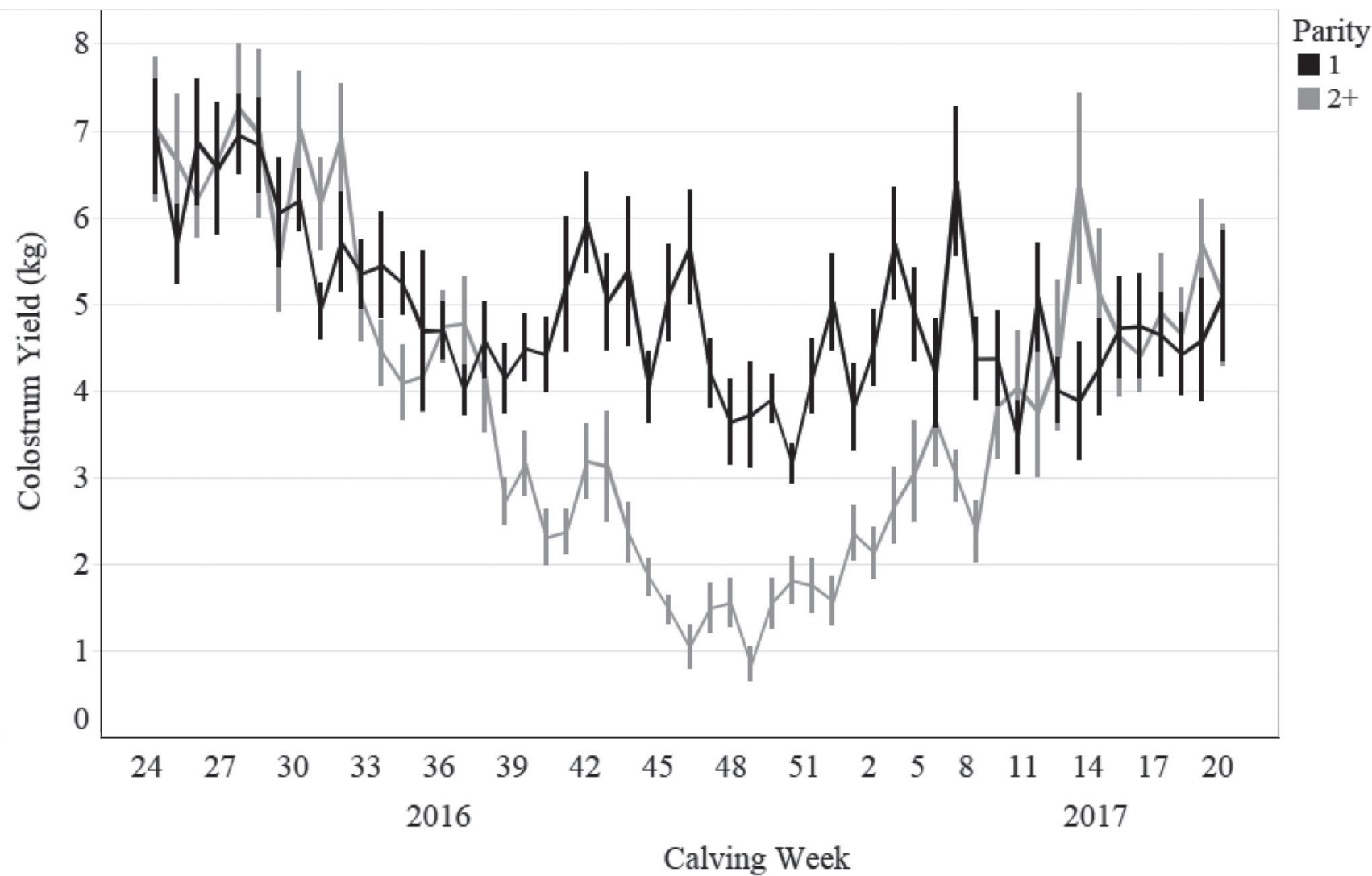

Figure 2. Average weekly colostrum weight and SD by week of freshening for first lactation and second lactation and greater in one Jersey cow herd $(\mathrm{n}=2,988)$.

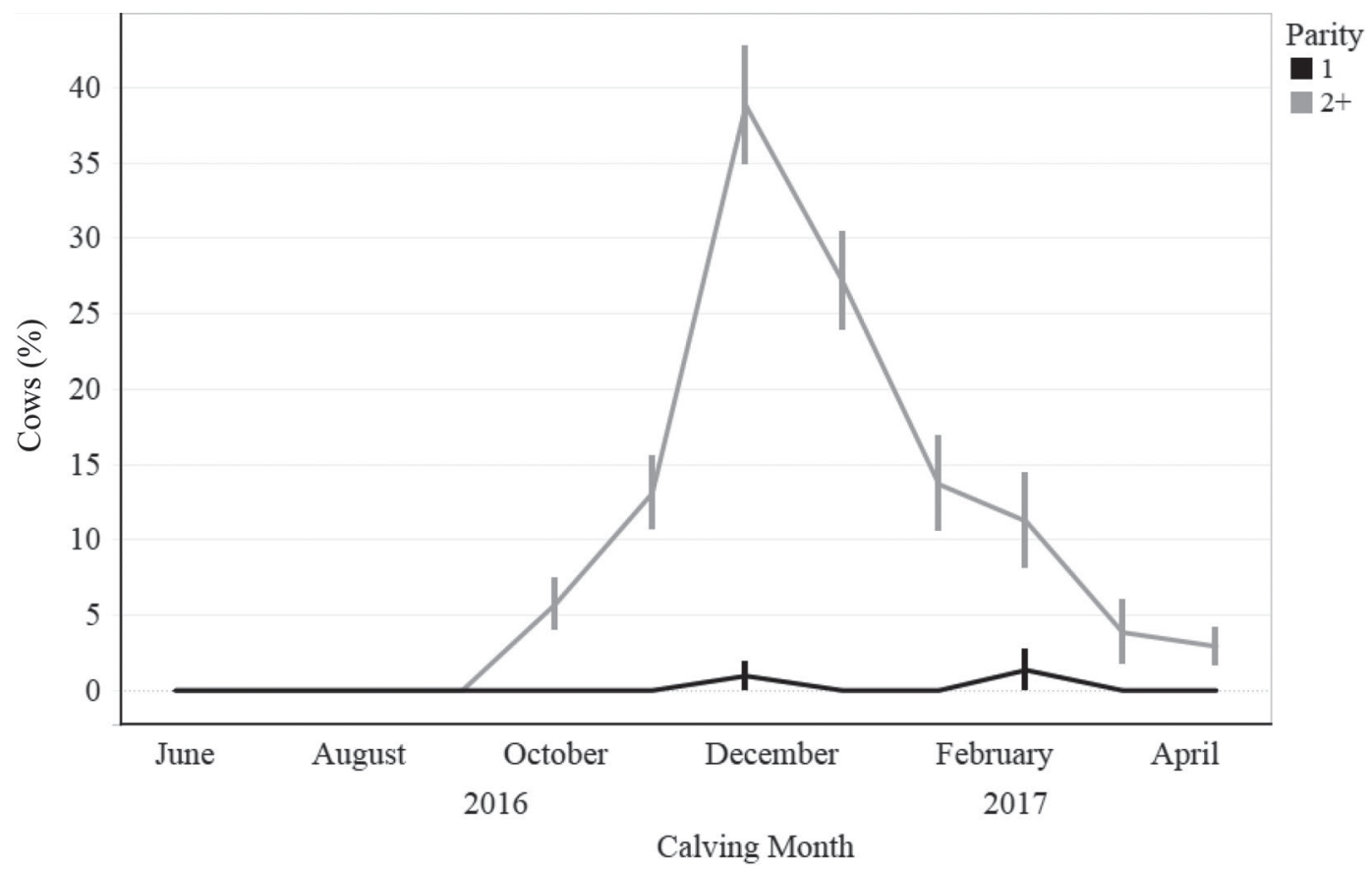

Figure 3. Percent of Jersey cows $(\mathrm{n}=2,988)$ in 1 herd with no colostrum produced and SE first milking by parity and month of calving. Journal of Dairy Science Vol. 101 No. 7, 2018 
Table 4. Logistic regression analysis for the probability of a cow producing less than $2.7 \mathrm{~kg}$ of colostrum at first milking

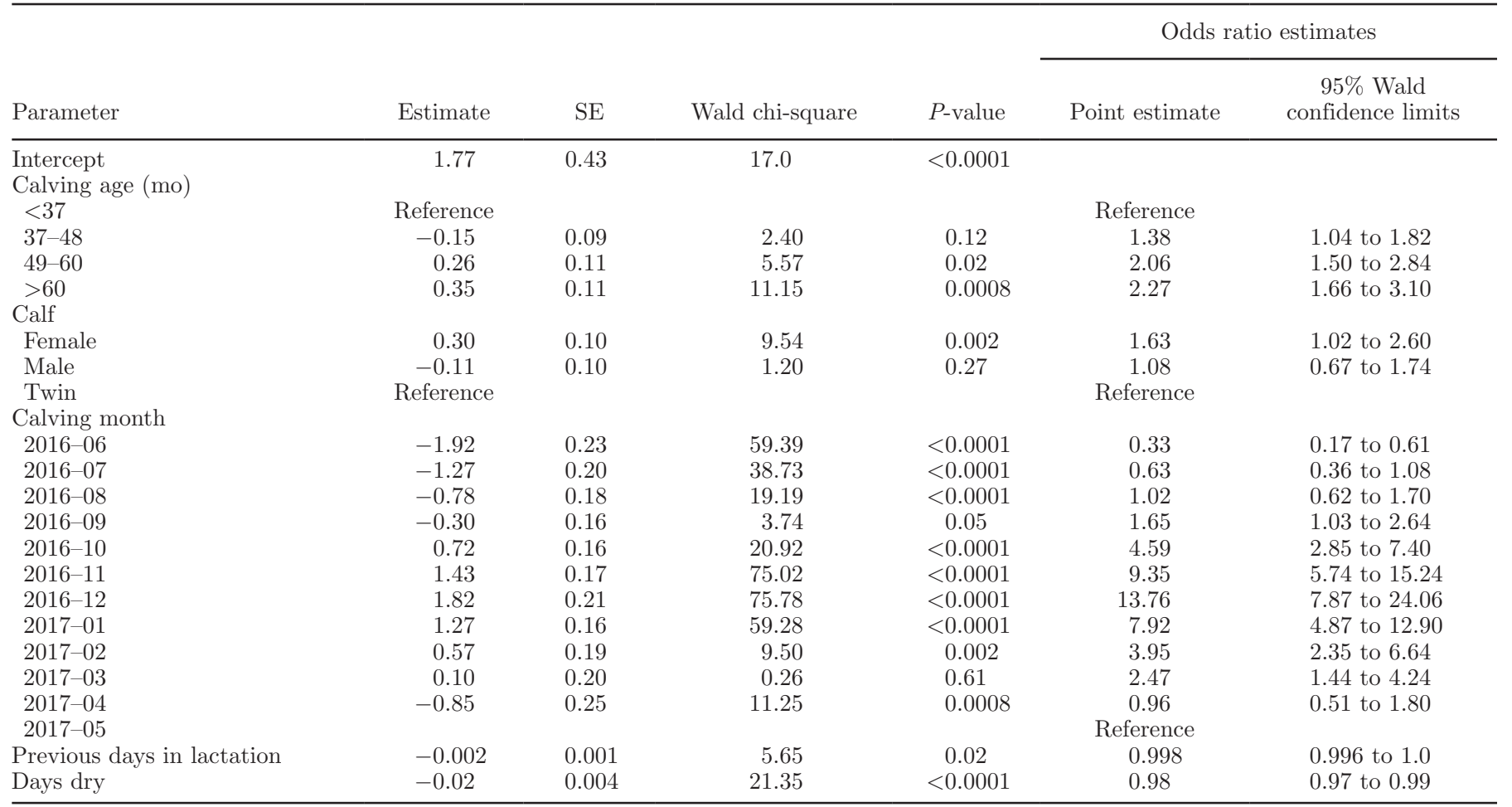

tion were significantly associated with low colostrum production, the effect estimates were small. Compared with a cow with a 75-d dry period, a cow with a 45-d dry period would have a 1.88 times greater odds of low colostrum production. Compared with a 65-d dry period, cows with dry periods of $45 \mathrm{~d}$ would have a 1.69 times greater odds of low colostrum production.

\section{Environmental Factors}

Graphically, average weekly colostrum weight for all cows appeared to follow photoperiod and maximum THI (Figure 4). A cross-correlation function with time lags of 0 to 12 mo was used to assess the correlation between colostrum production, THI, and photoperiod, stratified by lactation (Table 5). The highest correlations were seen between the series of multiparous cows' weekly colostrum yield and photoperiod, particularly at the time of calving and 1 mo before calving.

\section{Pedigree Analysis}

After pedigree analysis, the average coefficient of inbreeding for the 214 cows of the extremely low colostrum production group was $3.9 \%$. Further analysis revealed that several of the cows in the extreme group were half-siblings, with 5 males having sired 3 or more cows within the group (Table 6). These 5 sires had average daughter colostrum production values ranging from 0 to $8.77 \mathrm{~kg}$. Using a single-factor ANOVA, the colostrum weights for the offspring of each of these 5 sires were different between sire lines $(P=0.0002)$, sug-

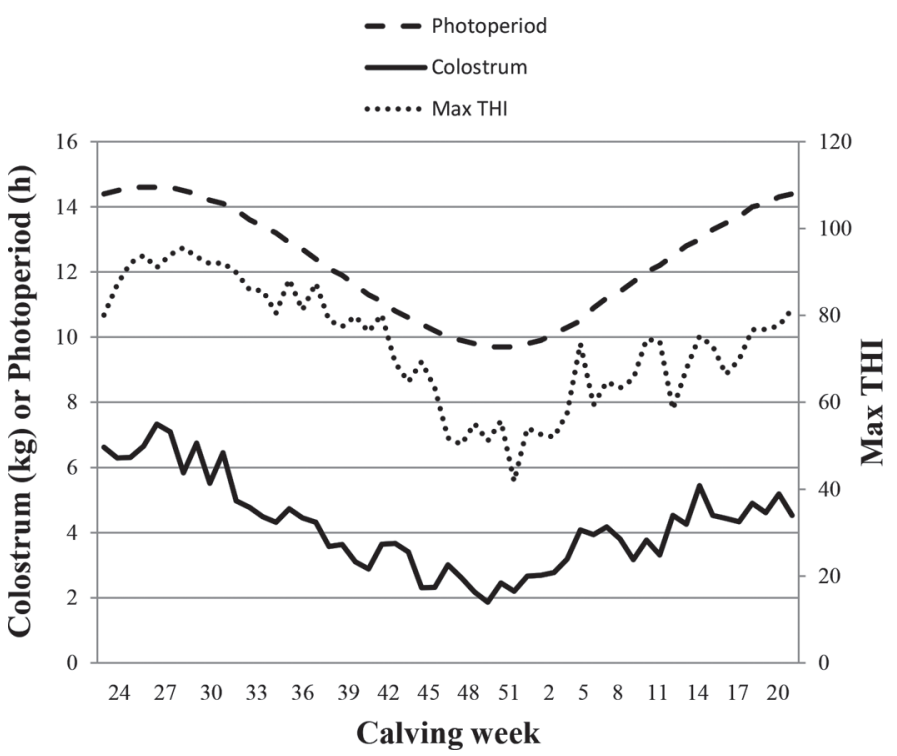

Figure 4. Photoperiod, average weekly colostrum weight, and maximum temperature humidity index (THI) by calving week for 2,988 Jersey cows on 1 farm. 
Table 5. Correlation coefficients between average weekly first milking colostrum production, temperature humidity index (THI), and photoperiod from a cross-correlation function analysis for the time series, June 1, 2016, to May 31, 2017

\begin{tabular}{|c|c|c|c|}
\hline \multirow[b]{2}{*}{ Item } & \multirow{2}{*}{$\begin{array}{l}\mathrm{Lag} \\
(\mathrm{m})\end{array}$} & \multicolumn{2}{|c|}{$\begin{array}{l}\text { Colostrum production } \\
\text { correlation coefficient (SE) }\end{array}$} \\
\hline & & Lactation 1 & Lactation $2+$ \\
\hline \multirow[t]{13}{*}{ THI } & 0 & $0.60(0.13)$ & $0.79(0.13)$ \\
\hline & 1 & $0.60(0.14)$ & $0.70(0.14)$ \\
\hline & 2 & $0.55(0.14)$ & $0.61(0.14)$ \\
\hline & 3 & $0.54(0.14)$ & $0.53(0.14)$ \\
\hline & 4 & $0.42(0.14)$ & $0.44(0.14)$ \\
\hline & 5 & $0.35(0.14)$ & $0.36(0.14)$ \\
\hline & 6 & $0.33(0.14)$ & $0.28(0.14)$ \\
\hline & 7 & $0.31(0.14)$ & $0.20(0.14)$ \\
\hline & 8 & $0.17(0.15)$ & $0.11(0.15)$ \\
\hline & 9 & $0.19(0.15)$ & $0.04(0.15)$ \\
\hline & 10 & $0.15(0.15)$ & $-0.07(0.15)$ \\
\hline & 11 & $0.08(0.15)$ & $-0.15(0.15)$ \\
\hline & 12 & $0.10(0.15)$ & $-0.25(0.15)$ \\
\hline \multirow[t]{13}{*}{ Photoperiod } & 0 & $0.53(0.13)$ & $0.91(0.13)$ \\
\hline & 1 & $0.48(0.14)$ & $0.84(0.14)$ \\
\hline & 2 & $0.51(0.14)$ & $0.77(0.14)$ \\
\hline & 3 & $0.48(0.14)$ & $0.71(0.14)$ \\
\hline & 4 & $0.43(0.14)$ & $0.65(0.14)$ \\
\hline & 5 & $0.40(0.14)$ & $0.56(0.14)$ \\
\hline & 6 & $0.37(0.14)$ & $0.47(0.14)$ \\
\hline & 7 & $0.35(0.14)$ & $0.40(0.14)$ \\
\hline & 8 & $0.27(0.15)$ & $0.32(0.15)$ \\
\hline & 9 & $0.34(0.15)$ & $0.21(0.15)$ \\
\hline & 10 & $0.25(0.15)$ & $0.10(0.15)$ \\
\hline & 11 & $0.22(0.15)$ & $0.03(0.15)$ \\
\hline & 12 & $0.18(0.15)$ & $-0.05(0.15)$ \\
\hline
\end{tabular}

gesting an underlying genetic component to seasonal colostrum deficiency in Jersey cattle.

\section{DISCUSSION}

Cows need to provide at least $2.7 \mathrm{~kg}$ of clean, quality colostrum to ensure adequate transfer of passive immunity to a Jersey calf. However, we found that first milking colostrum weights were highly variable depending on parity and time of the year, and many cows did not produce enough colostrum for their calf. Similar to previous studies, dry period length and age at calving were found to be significant factors influencing colostrum production (Pritchett et al., 1991). Whereas these differences were statistically significant, the magnitude of the effects were relatively small and these factors were not likely major reasons for the variation seen in our study. We also found previous lactation length to be a significant contributing factor, but the magnitude was also not a major source of colostrum yield.

As with dry period length and age at calving, weather has been implicated as a factor affecting colostrum production in other studies. From the cross-correlation function analysis, average maximum THI and photoperiod 1 mo before and at calving was most highly correlated with colostrum yield, with greater correlation in multiparous cows. The correlation of low THI and low colostrum yield in our study is different than that seen for milk production in that hotter weather is often association with lower milk yield. For example, a study in the northeastern United States examined the correlation between maximum daily temperature for $21 \mathrm{~d}$ before calving and colostrum yield and found that the number of days with a maximum temperature greater than $23^{\circ} \mathrm{C}$ was negatively correlated with colostrum yield (Cabral et al., 2016). Our observations could be explained by the fact that THI is strongly correlated with photoperiod. Caveats exist when interpreting these data because a correlation does not imply causation.

Photoperiod has been associated with hormones that are involved in colostrogenesis and lactogenesis (Auchtung et al., 2005), and could be a potential mechanism for the dramatic reduction in colostrum production in otherwise normal appearing Jersey cows. Several hormones that are involved in milk production, such as melatonin and prolactin, are also known to be linked to photoperiod. Similar to other mammals, daylight suppresses melatonin release from the pineal gland in cattle, resulting in low circulating melatonin levels during daylight hours and high circulating melatonin levels during times of darkness (Stanisiewski et al., 1988). Circulating melatonin levels downregulate the release

Table 6. Evaluation of the effect of sire on colostrum production for cows that calved from October 23, 2016, through January 21, 2017, in 7 Jersey cattle half-sibling families

\begin{tabular}{lccc}
\hline $\begin{array}{l}\text { Sire } \\
\text { identification }\end{array}$ & $\begin{array}{c}\text { No. of half-sibling } \\
\text { offspring }\end{array}$ & $\begin{array}{c}\text { Mean colostrum } \\
\text { production }(\mathrm{kg})\end{array}$ & $\begin{array}{c}\text { Average colostrum } \\
\text { production range }(\mathrm{kg})\end{array}$ \\
\hline 1 & 12 & 5.39 & $0-25.91$ \\
2 & 8 & 4.45 & $0-8.46$ \\
3 & 8 & 8.77 & $5.62-14.22$ \\
4 & 7 & 7.32 & $0-13.15$ \\
5 & 6 & 7.60 & $5.78-8.63$ \\
6 & 5 & 0 & $0-0$ \\
7 & 4 & 6.82 & $5.87-8.35$ \\
\hline
\end{tabular}


of hormones including prolactin and IGF-1 (Dahl et al., 2012). Prolactin is important to both lactating and dry cows, as it is responsible for the induction and maintenance of lactation. Lactating cows exposed to a longday photoperiod produced more milk and had higher circulating prolactin and IGF-1 levels compared with lactating cows exposed to a normal photoperiod (Dahl et al., 1997; Dahl and Petitclerc, 2003). In dry cows, a strong periparturient prolactin surge induces synthesis and secretion of $\alpha-\mathrm{LA}$ in prepartum bovine mammary tissue, as well as drives mammary secretory epithelial cell differentiation, and is therefore critical for induction of lactation (Akers, 1985; Auchtung et al., 2005; Dahl and Petitclerc, 2003). Photoperiod during the dry period has been shown to affect prolactin levels, presence of mammary prolactin receptors, and early lactation milk production. An inverse relationship exists between prolactin levels and presence of prolactin receptors in dry cows exposed to a short day photoperiod, as cows have decreased circulating prolactin but increased expression of prolactin receptor RNA in mammary tissue (Auchtung et al., 2005). The expression of mammary prolactin receptors in dry cows appears to be very important for subsequent milk production, as cows experiencing a short day photoperiod during the dry period have been shown to produce approximately $10 \%$ more milk during early lactation than cows experiencing a long day photoperiod during the dry period (Lacasse et al., 2014). Although evidence has shown that dry cow photoperiod affects early lactation milk production, the effect of photoperiod on colostrum has not been fully explored.

Our study found that colostrum production in multiparous cows was strongly correlated with photoperiod 1 mo before and at calving. This observation would suggest that colostrogenesis is regulated by photoperiod in a manner similar to how photoperiod regulates milk production levels in lactating cows rather than how dry period photoperiod affects early lactation milk production. This could be due to the aforementioned strong surge in prolactin levels before calving, known to be critical for induction of lactation, but it may also be important for colostrogenesis.

Genetics is another factor that could influence the colostrum production seen in our study. Evidence from the pedigree analysis supports a genetic component being involved in seasonal colostrum production, as colostrum production significantly varied between sire lines within the Jersey breed. A study of Holstein cows found that the predicted transmitting ability for milk, fat, and protein were significantly positively correlated with colostrum production and quality (Cabral et al., 2016). It remains a possibility that certain lines of cows are genetically predisposed to produce less colostrum, or are more affected by conditions such as photoperiod.

Several limitations in our study could be potential sources of bias. Environmental factors such as temperature, humidity, and photoperiod were accounted for but were not controlled. Although 2 employees were primarily responsible for processing newly calved cows and collecting and recording data, other employees were also occasionally involved. This could have resulted in slightly different methods for harvesting colostrum and recording data. Our study also did not evaluate the effect of clinical mastitis or elevated SCC during the previous lactation on colostrum yield because those data were unavailable. As previously noted, mastitis can negatively affect colostrum yield during the subsequent lactation (Maunsell et al., 1998). Other disease events were also not evaluated, but could potentially be risks for low colostrum yield.

Cow diets, specifically dry period diets, were not evaluated in our study. Target nutrient specifications were provided by the herd nutritionist and assumed not to vary significantly across the year. Only 2 studies have evaluated diet and colostrum yield. An ewe study looked at adequate versus deficient diets (Swanson et al., 2008), and the only cow study on the topic did not find significant differences in colostrum production between dry cows fed 100, 120, and $150 \%$ of their energy requirements. Our study did not control for potential changes in diet nor ration consumption by individual cows, as DMI influences energy consumption.

Future studies are needed to evaluate the effect of nutrition and genetics on colostrum production. Additionally, dairy herds in other areas of the United States should be evaluated to assess colostrum production in those locations. Finally, large-scale controlled trials manipulating photoperiod and THI during the dry period could evaluate the effect of these factors on colostrum yield in dairy cattle.

\section{CONCLUSIONS}

Colostrum production was affected by calving month and some cow factors, such as pedigree, dry period length, and calf characteristics. The dramatic swings in colostrum production across the year, and the fact that many cows produced no colostrum at first milking, indicate that this phenomenon has the potential to severely affect dairies by increasing calf morbidity or mortality through inadequate colostrum supplies for significant portions of the year, or result in higher costs for calf-rearing because colostrum replacer is needed. Appropriate colostrum banking is one strategy to address calf colostrum needs during low colostrum 
production months. Future research may help dairy producers manage the photoperiod and genetics of cows to improve colostrum production.

\section{ACKNOWLEDGMENTS}

The authors thank the dairy farm owner, manager, and staff for assistance with this study, and the Washington State University Department of Veterinary Clinical Sciences for support of the project.

\section{REFERENCES}

Akers, R. M. 1985. Lactogenic hormones: Binding sites, mammary growth, secretory cell differentiation, and milk biosynthesis in ruminants. J. Dairy Sci. 68:501-519.

Auchtung, T. L., A. G. Rius, P. E. Kendall, T. B. McFadden, and G. E. Dahl. 2005. Effects of photoperiod during the dry period on prolactin, prolactin receptor, and milk production of dairy cows. J. Dairy Sci. 88:121-127.

Box, G. E. P., and G. M. Jenkins. 1976. Time Series Analysis: Forecasting and Control. Rev. ed. Holden-Day, San Francisco, CA.

Cabral, R. G., C. E. Chapman, K. M. Aragona, E. Clark, M. Lunak, and P. S. Erickson. 2016. Predicting colostrum quality from performance in the previous lactation and environmental changes. J. Dairy Sci. 99:4048-4055. https://doi.org/10.3168/jds.2015-9868.

Collier, R. J., L. W. Hall, S. Rungruang, and R. B. Zimbleman. 2012 Heat stress and its impact on metabolism and performance. Accessed Jul. 22, 2017. http://shuresolutions.com/media/05-23-2012 _Quantifying_Heat_Stress.pdf

Dahl, G. E., T. H. Elsasser, A. V. Capuco, R. A. Erdman, and R. R. Peters. 1997. Effects of a long daily photoperiod on milk yield and circulating concentrations of insulin-like growth factor-1. J. Dairy Sci. 80:2784-2789.

Dahl, G. E., and D. Petitclerc. 2003. Management of photoperiod in the dairy herd for improved production and health. J. Anim. Sci. 81:11-17.

Dahl, G. E., S. Tao, and I. M. Thompson. 2012. Effects of photoperiod on mammary gland development and lactation. J. Anim. Sci. 90:755-760. https://doi.org/10.2527/jas.2011-4630.

Donovan, G. A., I. R. Dohoo, D. M. Montgomery, and F. L. Bennett. 1998. Associations between passive immunity and morbidity and mortality in dairy heifers in Florida, USA. Prev. Vet. Med. $34: 31-46$.

Dunn, A., A. Ashfield, B. Earley, M. Welsh, A. Gordon, M. McGee, and S. J. Morrison. 2017. Effect of concentrate supplementation during the dry period on colostrum quality and effect of colostrum feeding regimen on passive transfer of immunity, calf health, and performance. J. Dairy Sci. 100:357-370. https://doi.org/10.3168/ jds.2016-11334.

Faber, S. N., N. E. Faber, T. C. McCauley, and R. L. Ax. 2005. Case study: Effects of colostrum ingestion on lactational performance. Prof. Anim. Sci. 21:420-425.
Haredasht, S. A., C. J. Taylor, P. Maes, W. Verstraeten, J. Clement, M. Barrios, K. Lagrou, M. Van Ranst, P. Coppin, and D. Berckmans. 2013. Model-based prediction of Nephropathia epidemica outbreaks based on climatological and vegetation data and Bank vole population dynamics. Zoonoses Public Health 60:461-477. https://doi.org/10.1111/zph.12021.

Karimi, M. T., G. R. Ghorbani, S. Kargar, and J. K. Drackley. 2015. Late-gestation heat stress abatement on performance and behavior of Holstein dairy cows. J. Dairy Sci. 98:6865-6875. https://doi .org/10.3168/jds.2014-9281.

Kendall, M. G., and J. K. Ord. 1990. Time Series Analysis. 3rd Ed. Oxford University Press, New York, NY.

Lacasse, P., C. M. Vinet, and D. Petitclerc. 2014. Effect of prepartum photoperiod and melatonin feeding on milk production and prolactin concentration in dairy heifers and cows. J. Dairy Sci 97:3589-3598. https://doi.org/10.3168/jds.2013-7615.

Litherland, N. 2009. Nutrition factors causing low colostrum production. University of Minnesota Extension. Accessed May 21, 2016. https://www.extension.umn.edu/agriculture/dairy/transition -cows/nutrition-factors-causing-low-colostrum-production/.

Mann, S., F. A. Leal Yepes, T. R. Overton, A. L. Lock, S. V. Lamb, J. J. Wakshlag, and D. V. Nydam. 2016. Effect of dry period dietary energy level in dairy cattle on volume, concentrations of immunoglobulin G, insulin, and fatty acid composition of colostrum. J. Dairy Sci. 99:1515-1526. https://doi.org/10.3168/jds.2015-9926.

Maunsell, F. P., D. E. Morin, P. D. Constable, W. L. Hurley, G. C. McCoy, I. Kakoma, and R. E. Isaacson. 1998. Effects of mastitis on the volume and composition of colostrum produced by Holstein cows. J. Dairy Sci. 81:1291-1299.

McGuirk, S. M., and M. Collins. 2004. Managing the production, storage, and delivery of colostrum. Vet. Clin. North Am. Food Anim. Pract. 20:593-603. https://doi.org/10.1016/j.cvfa.2004.06.005.

Morin, D. E., S. V. Nelson, E. D. Reid, D. W. Nagy, G. E. Dahl, and P. D. Constable. 2010. Effect of colostral volume, interval between calving and first milking, and photoperiod on colostral IgG concentrations in dairy cows. J. Am. Vet. Med. Assoc. 237:420-428.

NRC. 2007. Nutrient Requirements of Small Ruminants: Sheep, Goats, Cervids, and New World Camelids. Natl. Acad. Press, Washington, DC.

Pattinson, S. E., and E. W. Thomas. 2004. The effect of sire breed on colostrum production of crossbred ewes. Livest. Prod. Sci. 86:4753. https://doi.org/10.1016/S0301-6226(03)00169-6.

Pritchett, L. C., C. Gay, T. Besser, and D. Hancock. 1991. Management and production factors influencing immunoglobulin g1 concentration in colostrum from Holstein cows. J. Dairy Sci. 74:2336-2341.

Stanisiewski, E. P., L. T. Chapin, N. K. Ames, S. A. Zinn, and H. A. Tucker. 1988. Melatonin and prolactin concentrations in blood of cattle exposed to 8, 12, or 24 hours of daily light. J. Anim. Sci. $66: 727-734$

Swanson, T. J., C. J. Hammer, J. Luther, D. Carlson, J. Taylor, D. Redmer, T. Neville, J. Reed, L. Reynolds, J. Caton, and K. Vonnahme. 2008. Effects of gestational plane of nutrition and selenium supplementation on mammary development and colostrum quality in pregnant ewe lambs. J. Anim. Sci. 86:2415-2423. https://doi .org $/ 10.2527 /$ jas. $2008-0996$

Taylor, C. J., D. J. Pedregal, P. C. Young, and W. Tych. 2007. Environmental time series analysis and forecasting with the Captain toolbox. Environ. Model. Softw. 22:797-814. 